\title{
ÉTICA: UM CAMPO EM CONSTANTE CONSTRUÇÃO
}

\section{Luana Elainy Rocha Magalhães ${ }^{1}$}

RESUMO: Este trabalho busca trazer reflexões acerca de algumas dimensões da ética na pesquisa e da responsabilização do pesquisador, mostrando sua complexidade e partindo do pressuposto de que se trata de um tema que suscitará sempre grandes dilemas ante a inviabilidade de esgotá-lo, tanto pela impossibilidade de conceituar ética de uma única forma, quanto por cada situação trazer questionamentos dantes não feitos, bem como pela escassez de instrumentos punitivos das associações de antropologia. Nessas reflexões sobre ética nas pesquisas que envolvem seres humanos, seja nas áreas humanas ou biomédicas, é importante compreender que ela se constrói à medida que vamos experienciando a vida. Normas de regulamentação, comitês de ética, são apenas balizadores, de modo que é a nossa consciência moral e a nossa vivência que efetivamente nos guiarão no melhor proceder. No que tange à responsabilização dos pesquisadores que falham com a ética, é necessário dar continuidade ao debate, mas também através deles trazer encaminhamentos que possam dar indicativos de soluções para a falta de instrumentos punitivos, bem como trazer à tona o trabalho do antropólogo, lembrando que esses sujeitos são pessoas e não objetos de pesquisa. A metodologia utilizada para a construção do artigo foi a bibliográfica.

Palavras-chave: Ética. Pesquisa. Campo. Responsabilidade.

\section{ABSTRACT}

This work was made to bring reflections on some dimensions of ethics on research and the researcher's responsability by showing its complexity and starting from the assumption that it is about a theme that will always raise great dilemmas due to the impossibility of exhausting it, not only because it is impossible to conceptualize ethics in a single way, but also that each situation brings up new questions that were not made before, as well as for the scarcity of punitive instruments of anthropological associations. In these reflections on ethics in research involving human beings, whether in the human or biomedical areas, it is important to understand that it is constructed as we experience life. Regulatory norms, ethics committees, are just beaconers, so it is our moral conscience and our experience that will effectively guide us in the best course of action. Regarding the responsability of researchers who fail with ethics, it is necessary to continue the debate so that it may provide guidelines that can give indications of solutions to the lack of punitive instruments, as well as it can highlight the work of the anthropologist, just reminding that these subjects are people and not only objects of research. The methodology used for this article was the bibliographical one.

Keywords: Ethics. Search. Field. Responsibility.

Ter uma boa bagagem teórica é um requisito importantíssimo para se realizar uma pesquisa. Além disso, é necessário saber escolher o melhor método para colher as informações que se almeja para obter o resultado esperado. Todavia, quando essa pesquisa envolve não objetos propriamente ditos, mas pessoas, é essencial mais que teoria, mais que uma boa técnica, é preciso ter ética, saber lidar com ela. Este trabalho tem por finalidade nos fazer refletir sobre algumas dimensões da ética na pesquisa e sua complexidade.

\footnotetext{
${ }^{1}$ Mestranda em Antropologia pela Universidade Federal do Piauí - UFPI. Advogada. Membro da Comissão de Direitos Difusos e Coletivos da OAB/PI. Especialização em Direito e Processo do Trabalho pela Faculdade CEUT. Bacharela em Direito pela Faculdade CEUT. E-mail: luanaelainy@hotmail.com
} 
Talvez se esteja pensando que então seria lógico iniciar com uma conceituação de ética, para então passarmos as reflexões. Contudo, tal expectativa há de ser frustrada, pois penso que o primeiro passo é justamente questionar "o que é ética?". Não com a ingênua crença de que encontraremos um conceito, mas de se questionar se sabemos de fato o que é, se conseguimos enquadrá-la em um conceito fechado que nos permita ao chegar a campo fazer um checklist para verificar se estamos ou não agindo eticamente.

Quem ousaria, além de Houaiss e Aurélio, conceituar ética? Fonseca (2010) inicia seu artigo mostrando que o primeiro traz algumas definições que apresentam em seu bojo a ideia de regras de ordem valorativa e traz exemplos sugerindo que cada profissão tem sua ética. Neste sentido, falaríamos em éticas, no plural. Eu trago Aurélio (2001, p. 300) que define ética como "estudo dos juízos humanos de apreciação referentes à conduta humana, do ponto de vista do bem e do mal" ou ainda "conjunto de normas e princípios que norteiam a boa conduta do ser humano".

Vejamos que o que eles nos trazem são também tentativas de se compreender o que é ética, porque, falar em "bem" e "mal" é deveras complicado, pois nos leva a tantos outros questionamentos. Seria uma filosofia sem fim. Bom, se não é possível definir o que é ética então nãoa colocaremos em prática, é o que você deve estar pensando. Mas, não é isso que estou sugerindo. A intenção é outra: é mostrar a complexidade do tema proposto.

\section{A complexidade da ética na pesquisa}

A pesquisa pressupõe uma bagagem teórica e metodológica e ao ser proposta passa por uma avaliação onde esses critérios serão ponderados. Outra etapa é a avaliação do Comitê de Ética, que composto por um colegiado multidisciplinar analisará se o projeto de pesquisa está eticamente adequado. Aqui, é preciso pensar no que consiste esta adequação.

Geertz(2001) estudando John Dewey, conclui que pensar é um ato social e que em longo prazo pode causar sérias consequências e por isso deve ser moralmente julgado. Neste sentido, Geertz(2001, p. 31) diz que "a qualidade moral da experiência dos cientistas sociais atuantes, a vida ética que levam enquanto fazem suas pesquisas, praticamente nunca é discutida, exceto nos termos mais genéricos".

A dimensão da ética na pesquisa é mais complexa e ampla do que se pode supor. Sendo assim,pode ser questionável o entendimento do Comitê de Ética ao classificar determinado projeto como eticamente adequado, se isso se dá única e principalmente pela presença de termos de assentimento livre e esclarecido dos participantes da pesquisa e/ou investigação da vida pregressa do pesquisador. 
Geertz (2001) considera o pensamento como uma conduta, como uma abstenção do agir e entende que a ética profissional está intrinsecamente ligada à ética pessoal, dela extraindo sua força. Desta forma caberia analisar a pesquisa de maneira mais profunda considerando a escolha do tema, a formulação do problema, a seleção e tratamento dos sujeitos pesquisados e ainda a linguagem na construção do texto final.

É isso que o autor fala que nunca é discutido e que Fonseca (2010, p.63) reforça quando diz:

Ao reconhecer que elementos éticos permeiam a pesquisa científica do início até o fim, torna-se patente que é ilusório imaginar ser possível regular esses elementos inteiramente através de instâncias formais. Qual comitê de ética - com quantos membros e quantas horas de discussão - daria conta da complexidade do campo?

Diante disso, a autora coloca em xeque a importância de tais comitês, uma vez que eles não são capazes de dar conta da complexidade de uma pesquisa de campo. E a própria autora responde que sua importância não reside em ditar o que é ou não ético, mas em suscitar o debate sobre as dimensões da ética na pesquisa. De fato, esse deve ser o papel desses comitês, posto que a ética é um campo que está em constante construção, pois não é algo fixo, mas mutável de acordo com a época, com os valores adotados, com os sujeitos envolvidos e com as situações vividas.

Ainda no que tange a atuação dos comitês de ética, é importante falar do assentimento livre e esclarecido, que de acordo com a Resolução no 510 de 2016 do Conselho Nacional de Saúde consiste na:

(...) anuência do participante da pesquisa: criança, adolescente ou indivíduos impedidos de forma temporária ou não de consentir, na medida de sua compreensão e respeitadas suas singularidades, após esclarecimento sobre a natureza da pesquisa, justificativa, objetivos, métodos, potenciais benefícios e riscos. A obtenção do assentimento não elimina a necessidade do consentimento do responsável.(grifo meu)

Na definição acima o que seria a anuência na medida de sua compreensão e respeitadas as suas singularidades? Significaria que os sujeitos pesquisados não precisam entender de fato a natureza, justificativa, objetivos, métodos, benefícios e riscos da pesquisa? Não se trata aqui de crítica à resolução citada, que se ressalte é um grande avanço para área das ciências sociais, mas de chamar atenção de um modo geral às pesquisas realizadas em todas as áreas com seres humanos, no que diz respeito à vulnerabilidade dos sujeitos envolvidos.

Na seara das pesquisas com seres humanos, há que se considerar a vulnerabilidade do grupo que se pretende pesquisar, pois o consentimento dado pode a ela estar condicionado. $\mathrm{O}$ primeiro ponto a se considerar é que o termo em especial quando escrito não é negociável, é um termo de adesão, existem duas opções: aceitar ou não. Mas dependendo do sujeito e das circunstâncias a recusa pode não ser uma alternativa tão evidente, pois o cientista é historicamente visto como o 
detentor do conhecimento, que sabe usar as palavras, que fala bem e está acima de quaisquer suspeitas por estar sob o manto da imparcialidade.

Fonseca (2010, p. 45) tratando dessa vulnerabilidade comenta alguns casos, dentre eles o da pesquisa de um médico norte-americano:

Em 1966, um médico da Universidade de Harvard, Henry Beecher, publicou um levantamento de 22 projetos desenvolvidos por cientistas norte-americanos, todos altamente qualificados, em que a saúde das pessoas envolvidas tinha sido gravemente prejudicada pela pesquisa. Uma das conclusões mais alarmantes do estudo de Beecher era que boa parte da experimentação ocorria em populações vulneráveis: recrutas militares, portadores de deficiência mental, idosos, presos, crianças, etc. A pergunta que se colocava era: esses indivíduos estão em condições de negociar os termos de sua participação numa pesquisa acadêmica? Tornou-se evidente que existiam situações em que a questão ética ia muito além do simples consentimento livre e esclarecido.

Portanto, o que se pode inferir é que como dito alhures é impossível confinara ética num conceito, da mesma forma é inviável assegurar que a pesquisa será desenvolvida de maneira ética em razão da existência de um consentimento que pode não ser tão livre assim e talvez sequer tenha sido realmente esclarecido pelo pesquisador ou se foi, pode não ter sido a pesquisa compreendida em suas dimensões gerais ou até específicas pelos participantes.

Diante do exposto, surge a pergunta: mas e quando não há, pelo menos de forma evidente, uma vulnerabilidade do pesquisado em relação ao pesquisador? Bom, aí precisamos chamar para o debate outra antropóloga, Guita Grin Debert, que já fez esse mesmo questionamento. E assim Debert (2001, p. 46) nos provoca dizendo: “É parte da responsabilidade do antropólogo denunciar (...) o caráter das práticas que podem ser nefastas para a sociedade como um todo ou para os grupos que tradicionalmente têm sido estudados pela antropologia”.

A autora não nos dá uma resposta fechada, mas nos leva a refletir sobre até que ponto em determinados contextos devemos de fato ser tão transparentes em nossas intenções e explicações sobre a pesquisa e se questiona se em casos onde o pesquisador deva agir com sua responsabilidade profissional não seria aí o caso de manipular a ética. Distinto não é o posicionamento do antropólogo Cardoso de Oliveira (2001, p. 28), segundo o qual:

A eqüidistância moral e política, recomendada pela antiga academia, parece não se justificar nos dias de hoje. Mesmo porque, a partir da evidência de que não existe objetividade absoluta, sendo ela portanto uma mera ilusão - o que, é bom lembrar, não implica em exorcizar toda e qualquer objetividade, mas somente o objetivismo -, o espaço de ação do pesquisador não pode ficar vazio, pois nesse caso estaria sendo ocupado por funcionários, políticos ou administradores não ou pouco comprometidos(...)

Eis aí um grande desafio a ser enfrentado pelos pesquisadores, conciliar a responsabilidade profissional com a ética. Pois pelo que podemos perceber nem sempre elas estarão sintonizadas. 
Outra dimensão importante e também complexa é a relação entre pesquisador e pesquisados/informantes. É uma dimensão extremamente delicada da pesquisa em que todo o arcabouço teórico não é capaz de abranger. Apenas a dimensão ética é capaz de dar conta desta relação. E como Geertz disse a ética profissional está umbilicalmente ligada à ética pessoal. Entendo que são coisas indissociáveis, pois como diz o ditado popular "o costume que se tem em casa se leva à praça”.

O campo não desafia apenas nosso conhecimento teórico e a capacidade de perceber o que é importante etnograficamente. Antes de nos desafiar como pesquisadores o campo nos desafia como pessoas. É neste mesmo sentido que Cardoso de Oliveira (2006, p. 21) fala de seu desejo em recuperar a preocupação com a moralidade "como alvo legítimo do trabalho de uma antropologia comprometida não apenas com a busca de conhecimento sobre seu objeto de pesquisa, mas sobretudo com a vida dos sujeitos submetidos à observação"

Ao trabalhar sobre a questão moral na pesquisa trazendo como pano de fundo suas estudos com os novos países da Ásia e da África relacionados à modernização das sociedades tradicionais, Geertz (2001, p. 33) coloca a situação precária dessas sociedades em que os habitantes - a depender da perspectiva, das definições usadas - teriam subempregos, mas diz que segundo um economista, modernizar Java permitiria que o "trabalho agrícola fosse realizado por apenas $10 \%$ da força de trabalho, mas que isso reduziria à fome os outros $90 \% "$.

O exemplo citado por Geertz nos diz que antes de tentar solucionar aquilo que para nós é um problema para a comunidade é imperioso realizar o exercício mental de questionar as consequências disso, sob pena de causar o mal-estar ético do qual Roberto Cardoso de Oliveira fala. Ademais, no trato com as pessoas pesquisadas, é preciso ter minimamente feeling para saber lidar com as particularidades de cada uma delas e ter o cuidado ao expor o conhecimento científico para que não seja uma imposição.

Sobre isso Roberto Cardoso de Oliveira (2006) trabalha a partir de uma perspectiva de três esferas éticas, a micro, a meso e a macro. De maneira simples e resumida, a micro corresponderia ao espaço ocupado pelos sujeitos observados, à comunidade, com suas crenças, sua cultura, ao passo que a macro seria a sociedade - estado nacional, “o espaço universal”. Diante disso, haveria a meso esfera que corresponderia ao antropólogo, que faria a mediação, a ligação entre os sujeitos pesquisados e o "resto do mundo", ou mais especificamente entre os valores de um e os valores do outro.

É ocupando o espaço na meso esfera que se cria tal mal-estar, assim explica Cardoso de Oliveira (2006, p. 23), ele diz: "E nessa condição mediadora entre culturas - e mais do que isso, entre pessoas de carne e osso - insere-se o antropólogo e lhe deixa muitas vezes numa situação de 
tal desconforto ou, melhor ainda, (...) cria-lhe um indefectível mal-estar ético". O autor nos leva, portanto, à percepção de que tal mal-estar é inevitável, pois o pesquisador será colocado nesta posição de mediador queira ele ou não. Sendo assim, o que nos resta é refletir sobre como agir diante de situações em que nos cabe mediar os valores culturais de dois grupos.

Mas antes de chegar a esse ponto de mediador, existe o momento mais inicial da pesquisa, quando do recrutamento de informantes, para qual Geertz chama nossa atenção, nos alertando para a ilusão que tanto o pesquisador quanto o informante criam de que pertencem ao mesmo universo cultural. Tal ilusão é até compreensível, posto nosso desejo ávido por uma relativização cultural que, contudo, se faz muitas vezes sem critérios críticos e realistas onde deixamos de lado que somos pessoas dotadas de valores.

Não se trata de nos colocarmos cada um em seu lugar num caráter de segregação, mas de ter a sensibilidade de perceber que valores e trocas estão em jogo. O próprio fato de haver um sujeito pesquisador e um sujeito pesquisado já deixa evidente que estão em locais/posições diferentes.

Também não se trata de se manter um distanciamento objetivo dos sujeitos, mas de na construção da relação com eles saber que há uma tensão, ainda que adormecida, que pode vir à tona no mínimo deslize, numa atitude que para nós pode não ser significativa, mas para eles pode ter imenso valor. É isso que não se pode perder de vista, é uma atitude que deve ser vivida com os nossos e com os outros, em especial pela condição de vulnerabilidade na qual geralmente se encontram.

\section{Sobre a responsabilidade ética de quem pesquisa}

- Mas não vai colocar na internet não, porque, meu marido é muito zangado, porque hoje, tudo se coloca na internet, aí já pensou se ele vê isso?

Essa foi a preocupação de uma das minhas entrevistadas, durante a pesquisa de mestrado. Ela me relatou sobre uma tentativa de processo de divórcio de seu atual marido, sim, pois em razão da burocracia judicial ela acabou por desistir do divórcio. Trata-se de caso de violência doméstica. Alegou a senhora que hoje não apanhava mais do marido, que ele mudou, mas seu receio sobre a publicação da entrevista e do seu nome denunciavam que não era bem assim. Expliquei a ela que não se preocupasse, que por questões éticas nós não usávamos os nomes verdadeiros das pessoas que entrevistamos, pois entendíamos que elas poderiam se prejudicar e com isso nós pesquisadores - seríamos responsabilizados pelo dano causado.

Fiquei pensando, porém, que punição receber um antropólogo ou qualquer outro pesquisador por ter falhado com a ética em sua pesquisa. Como de fato seremos responsabilizados 
caso tenhamos essa falha de caráter, sim porque, é impossível que ética e caráter não estejam ligados?! Luís Roberto Cardoso de Oliveira (2010) nos lembra bem, que essa é também uma questão complexa no debate sobre a ética, tanto aqui no Brasil como lá fora. É complexo justamente pela pergunta que fiz: como responsabilizar?

Os instrumentos dos quais dispõe a Associação Brasileira de Antropologia, bem como a Associação Americana de Antropologia - dos Estados Unidos - são poucos, na verdade limitandose à notas de repúdio. A nota de repúdio constitui um texto em que o órgão manifestar a sua discordância com a prática do pesquisador, mostrando que não coaduna com atitudes que violem a ética na pesquisa.

Mas que de que forma, essa nota de repúdio de fato pune e restaura o status quo ante dos sujeitos prejudicados com a pesquisa? Como desfazer uma possível violência sofrida a essa mulher - minha sujeita - por parte do marido, após ver seus nomes expostos nas redes sociais ou divulgados em outros meios que tornasse possível o seu conhecimento do trabalho e assim suas histórias fossem expostas? Algum instrumento tem essa capacidade, de fato? "A reflexão ética deve nos remeter tanto às relações de pesquisa quanto aos impactos que o trabalho etnográfico pode ter na vida das pessoas". (FERREIRA, 2010, p. 141)

Como vimos, definir o que é ética também não é nada fácil, dessa dificuldade nasce uma outra questão ainda mais complexa, qual o limite, o que separa a falta de ética de uma autocrítica crítica aos pares? Oliveira (2010, p. 26) nos traz o relato que exemplifica/justifica a pergunta:

Durante quase um século, a AAA tinha mecanismos e procedimentos para penalizar
antropólogos que saíam, digamos assim, da orientação básica, dos princípios éticos da
disciplina. No entanto, durante todo esse período, só foi punido um antropólogo: Franz
Boas, conhecido como a principal referência na formação da Escola Histórico-Cultural, que
marca a disciplina nos Estados Unidos. E a AAA puniu Boas por críticas que ele fez à
atuação ou à suposta atividade de antropólogos estadunidenses como espiões na Primeira
Guerra Mundial. A punição a Boas foi revista apenas em 2005, muitos anos após o
falecimento do antropólogo.

O trecho acima dá um indicativo de que o que separa uma coisa da outra é uma linha bem tênue. E as consequências podem ser de certo modo irreversível. Boas, tivera sua situação revista, mas jamais soubera ou saberá disso. Isso retoma ao que foi falado antes, de como a ética é vulnerável ao tempo e aos sujeitos que a definem. A possibilidade de rever se a atitude de Boas fora uma crítica ou uma falha ética, deixa evidente essa característica da ética, que varia ao longo do tempo e de acordo com o contexto vivido.

Nesse sentido, considerando as possibilidades de variação da significação do que seja ética, e o que seja ético fazer ou não fazer, cabe falar daquilo que pode ser atemporal: as responsabilidades ou como diz Oliveira (2010) os compromissos éticos do pesquisador, quais sejam: o compromisso com a verdade e a produção de conhecimento, o compromisso com os 
sujeitos da pesquisa, e o compromisso com a sociedade e a cidadania. Estes são compromissos básicos - cláusulas pétreas, como se diz no Direito- que podem nos nortear a agir em consonância com a ética, sem causar danos em especial aos sujeitos pesquisados.

Ferreira (2010) nos faz refletir sobre como conversar com os nativos, isto é, os sujeitos do campo de pesquisa, como uma forma de saber ouvir, de saber conversar para não distorcer o que eles falam. Nessa perspectiva importante trazer Cardoso de Oliveira (2000), que fala sobre o trabalho do antropólogo, no qual tem seu sustento no ouvir, falar e escrever, faculdades fundamentais na construção do saber.

De acordo com o autor o olhar deve estar sensibilizado pela teoria para poder ter contato com o campo de modo a estabelecer suas prefigurações. Do mesmo modo o ouvir deve estar disciplinado para que obtenha perfeita compreensão do sentido e da significação da fala nativa. Importante ainda, e talvez de maior peso é a habilidade de escrever, que é inseparável do pensamento, pois é a escrita que publicará os resultados acerca da observação e da conversação com os sujeitos pesquisados, devendo sempre ser refeito, revisto, antes de pôr um ponto final. Realizar bem o trabalho antropológico é em certa instância estar sincronizado com os compromissos que são necessários para se alcançar a ética na pesquisa.

\section{Considerações finais}

Nessas reflexões sobre ética nas pesquisas que envolvem seres humanos, seja nas áreas humanas ou biomédicas, é importante compreender que ela se constrói à medida que vamos experienciando a vida. Normas de regulamentação, comitês de ética, são apenas balizadores, de modo que é a nossa consciência moral e a nossa vivência que efetivamente nos guiarão no melhor proceder.

Apesar de todas as limitações que instâncias formais possam ter diante da complexidade das pesquisas que envolvem seres humanos, em especial em pesquisas de campo onde o pesquisar constrói uma relação mais intima com os sujeitos observados, não se pode falar de sua desnecessidade.

Há que se repensar a atuação dessas instâncias de modo que elas mais do que analisar pontos objetivos, fomentem o debate sobre questões éticas, desde o projeto até a construção do resultado final. E considere a atuação do pesquisador tanto em situações de vulnerabilidade dos sujeitos pesquisados quanto em casos onde o compromisso profissional possa ir de encontro com a ética, ou com aquilo que se considere ser ético. Em suma talvez seja o caso de se compreender que a ética apresenta várias dimensões que variam conforme as condições da pesquisa. 
De modo geral, quando, em nossa meso esfera, formos chamados a intervir, não são os regulamentos ou comitês que nos valerão, pois não haverá tempo, - e mesmo que houvesse tempo, nenhuma resposta nos dariam, ou nos dariam tantas quantos fossem o número de membros - dessa forma faz-se necessário atuar com comprometimento, respeitando as singularidades dos sujeitos envolvidos, incentivando-os para que eles sejam protagonistas. Fato é que em razão da ética está em constante construção estaremos sempre vivendo um dilema ético a cada nova situação.

No que tange à responsabilização dos pesquisadores que falham com a ética, é necessário dar continuidade ao debate, mas também através deles trazer encaminhamentos que possam dar indicativos de soluções para a falta de instrumentos punitivos, bem como trazer à tona o trabalho do antropólogo, em seu ouvir, falar e escrever, como atividade que exige sensibilidade e compromisso com o saber, mas acima de tudo com os sujeitos, lembrando que esses sujeitos são pessoas e não objetos de pesquisa.

\section{REFERÊNCIAS}

CARDOSO DE OLIVEIRA, Roberto. 2000. “O trabalho do antropólogo: olhar, ouvir, escrever”. In O Trabalho do Antropólogo. São Paulo: UNESP, pp 17-35.

. O mal-estar da ética na antropologia prática. Antropologia e ética: o debate atual no Brasil. Niterói: EdUFF, 2004. pp 21-32.

CONSELHO NACIONA DE SAÚDE. Resolução n 510, de 07 de abril de 2016. Disponível em: <http://conselho.saude.gov.br/resolucoes/2016/Reso510.pdf>. Acesso em 03/07/2016.

DEBERT, Guita Grin. Ética e as novas perspectivas da pesquisa antropológica. Antropologia e ética: o debate atual no Brasil. Niterói: EdUFF, 2004. pp45-54.

FERREIRA, Aurélio Buarque de Holanda. Miniaurélio Século XXI Escolar: o minidicionário da língua portuguesa. Rio de Janeiro; Nova Fronteira, 2001.

FERREIRA, Luciane Ouriques.A dimensão ética do diálogo antropológico: aprendendo a conversar com o nativo. In: FLEISCHER, Soraya \&SCHUCH, Patrice (orgs.) Ética e Regulamentação na Pesquisa Antropológica. Brasília: LetrasLivres, Ed. UnB(2010). pp 141-158.

FONSECA, Claudia. Que ética? Que ciência? Que sociedade?. In: FLEISCHER, Soraya \&SCHUCH, Patrice (orgs.) Ética e Regulamentação na Pesquisa Antropológica. Brasília: LetrasLivres, Ed. UnB(2010). pp 39-70.

GEERTZ, Clifford. O pensamento como ato moral: dimensões éticas do trabalho de campo antropológico em países novos. In: Nova luz sobre a antropologia. Rio de Janeiro: Jorge Zahar Ed., 2001. pp 30-46. 
OLIVEIRA, Luis Roberto Cardoso de. A antropologia e seus compromissos ou responsabilidades éticas.In: FLEISCHER, Soraya \&SCHUCH, Patrice (orgs.) Ética e Regulamentação na Pesquisa Antropológica. Brasília: LetrasLivres, Ed. UnB(2010). pp 25-38. 